\title{
Localization and characterization of $\gamma$-glutamyl cyclotransferase in cancer cells
}

\author{
KAORU AZUMI ${ }^{1}$, YOUHEI IKEDA ${ }^{1}$, TOMOHARU TAKEUCHI ${ }^{1}$, TSUYOSHI NOMURA ${ }^{1}$, \\ SORIN V. SABAU ${ }^{4}$, JUN-ICHI HAMADA ${ }^{2}$, FUTOSHI OKADA ${ }^{5}$, \\ MASUO HOSOKAWA ${ }^{3}$ and HIDEYOSHI YOKOSAWA ${ }^{1}$
}

\begin{abstract}
${ }^{1}$ Department of Biochemistry, Graduate School of Pharmaceutical Sciences, Hokkaido University, Sapporo 060-0812; Divisions of ${ }^{2}$ Cancer-related Genes, and ${ }^{3}$ Cancer Pathobiology, Institute for Genetic Medicine, Hokkaido University, Sapporo 060-0815; ${ }^{4}$ Center for Computer Science and Education, Hokkaido Tokai University, Sapporo 005-8601; ${ }^{5}$ Department of Biomolecular Function, Graduate School of Medical Science, Yamagata University, Yamagata 990-9585, Japan
\end{abstract}

Received October 1, 2008; Accepted January 19, 2009

DOI: $10.3892 / \mathrm{mmr}+00000110$

\begin{abstract}
Using differential display analysis, we have identified a novel rat gene whose expression is increased during tumor progression in rat mammary carcinoma cell lines. This gene is an ortholog of the human chromosome 7 open reading frame 24 gene (C7orf24) and encodes a protein of 188 amino acids with no recognized protein domains. C7orf24 has been identified as $\gamma$-glutamyl cyclotransferase (GGCT), an important enzyme functioning in glutathione homeostasis. Our Northern and Western blot analyses revealed that the GGCT gene is expressed in various normal human and tumor tissues, as well as in cancer cell lines. Among the tumor tissues tested, lung tumor tissue expressed GGCT mRNA more strongly than normal lung tissue. The GGCT protein was found to be localized in the cytoplasmic region of cultured cells, where it forms a homodimer. Analysis of various deletion mutants of the GGCT protein revealed that the region containing amino acid residues $61-120$ of the protein is required for its cytoplasmic localization. The comparison of the soft agar colony formation of HBL-100 cells stably expressing GGCT with that of control HBL-100 cells revealed that GGCT does not promote colony formation, suggesting that the role it plays in lung cancer cells is not related to tumorigenesis.
\end{abstract}

\section{Introduction}

Tumor progression is a complex and multi-step process in which tumor cells acquire malignant properties, including the

Correspondence to: Dr K. Azumi, Department of Biochemistry, Graduate School of Pharmaceutical Sciences, Hokkaido University, Kita 12, Nishi 6, Kita-ku, Sapporo 060-0812, Japan

E-mail:kaoru@pharm.hokudai.ac.jp

Key words: differential display, $\gamma$-glutamyl cyclotransferase, chromosome 7 open reading frame 24 , gene expression, lung tumor, cytoplasmic localization capacity for aggressive growth, migration, invasion and metastasis (1-3). In order to study the mechanisms of tumor progression, Hamada et al established an in vivo experimental model based on rat ER-1 and ERpP cell lines (4-7). The weakly malignant cell line ER-1, derived from a highly metastatic rat mammary adenocarcinoma cell line, c-SST-2, showed only weak tumorigenicity and a lack of metastasis when injected subcutaneously (s.c.) into syngeneic rats as a single cell suspension. However, when ER-1 cells attached to a small piece of plastic plate were implanted s.c., they acquired tumorigenicity and metastasized to the lung. On the other hand, the ERpP cell lines established from the tumors arising from plate-attached ER-1 cells possessed tumorigenic and metastatic properties in the lungs of normal rats, without the need for plastic plates. Tumor progression derived from ER-1 cells was induced not only by implanting the cells together with plastic plates, but also by exposure to epidermal growth factor (EGF) or transforming growth factor (TGF)- $\beta(6,8,9)$. Thus, ER-1 cell progression is thought to be a result of inflammation induced by inoculation with plastic plates or exposure to EGF/TGF- $\beta$ in vitro. However, its molecular mechanisms remain unclear.

To clarify the molecular mechanisms underlying ER-1 cell progression, we analyzed genes that were differentially expressed in ER-1, EGF-treated ER-1 and ERpP cells using a differential display method. We found several genes that were up-regulated in EGF-treated ER-1 and ERpP cells in comparison with ER-1 cells. One of these genes, rat 18c, was found to be an ortholog of the human gene chromosome 7 open reading frame 24 (C7orf24; accession ID BC019243), a novel gene registered in the NCBI database. C7orf24 encodes a protein of 188 amino acids with no recognized protein domain. The C7orf24 protein was tentatively identified as a cytochrome c-releasing factor present in the cytosolic fraction of human leukemia U937 cells treated with geranylgeraniol, and exhibited apoptosis-inducing activity (10). A bioinformatics study using DNA microarray analysis of the tumor or normal tissues of patients revealed that $\mathrm{C} 7$ orf 24 is a potential cancer marker (11). C7orf24 gene expression was increased 
in the lung and brain tumors of some patients. Recently, C7orf24 was fully identified as $\gamma$-glutamyl cyclotransferase (GGCT, EC2.3.2.4) (12). GGCT is an essential enzyme that catalyzes the formation of 5-oxoproline from $\gamma$-glutamyl dipeptides in the $\gamma$-glutamyl cycle. A crystallo-graphic analysis revealed that GGCT is a dimer of $21 \mathrm{kDa}$ subunits (12).

In the present study, we confirmed by Northern blot analysis that GGCT mRNA was increased in lung tumor compared with normal lung tissues. We developed an antiGGCT polyclonal antibody and used it to demonstrate dimerization of the GGCT protein and its cytoplasmic location in cancer cells. The establishment of a cell line that stably expressed GGCT and the measurement of its colony formation revealed that GGCT does not promote colony formation, which led us to assume that in some tumor cells the role played by GGCT involves something other than tumorigenesis.

\section{Materials and methods}

Cell culture. Cell lines were cultured in Dulbecco's modified Eagle's medium (DMEM) (Sigma-Aldrich) supplemented with $10 \%$ heat-inactivated fetal bovine serum (FBS) (Invitrogen), $100 \mathrm{U} / \mathrm{ml}$ penicillin and $100 \mu \mathrm{g} / \mathrm{ml}$ streptomycin in $5 \% \mathrm{CO}_{2}$ and $95 \%$ air at $37^{\circ} \mathrm{C}$. MDA-MB-453 and HBL-100 cells were purchased from RIKEN BioResource Center (Tsukuba, Ibaragi, Japan). ER-1-24h and ER-1-1M cells were produced by culturing ER-1 cells with $100 \mathrm{ng} / \mathrm{ml}$ human recombinant EGF (Wakunaga Pharmaceutical) for $24 \mathrm{~h}$ and 1 month, respectively. In the case of the ER-1-1M cells, human EGF was added every $24 \mathrm{~h}$.

Differential display. The ER-1, ER-1-24h, ER-1-1M and ERpP cell lines were cultured until they reached $70-80 \%$ confluence. Total RNA was extracted from each cell line using TRIzol reagent (Invitrogen), and was then digested with DNase I (Takara Bio) for $30 \mathrm{~min}$ at $37^{\circ} \mathrm{C}$. Fluorescent differential display was performed according to a previously described method (13). DNase-treated total RNA $(2.5 \mu \mathrm{g})$ was primed with $5 \mu \mathrm{M}$ fluorescein (FITC)-labeled GT15X (X=A, C or G) (anchor primer) at $70^{\circ} \mathrm{C}$ for $10 \mathrm{~min}$, and cDNA was synthesized using 200 units of SuperScript II reverse transcriptase (Invitrogen) according to the manufacturer's protocol. DNA was amplified by polymerase chain reaction (PCR) using FITC-labeled anchor primer and arbitrary primers (Operon Biotechnologies). cDNA template $(2 \mu \mathrm{l})$ was added in a $20-\mu \mathrm{l}$ reaction mixture consisting of $1 \mathrm{X}$ GeneTaq buffer (Nippon Gene, Tokyo, Japan), $1.5 \mathrm{mM} \mathrm{MgCl} 2,0.5 \mu \mathrm{M}$ FITC-labeled anchor primer, $0.5 \mu \mathrm{M}$ arbitrary primer, $50 \mu \mathrm{M}$ of each dNTP, 0.5 units of GeneTaq DNA polymerase (Nippon Gene) and 0.5 units of AmpliTaq DNA polymerase (Perkin-Elmer). The thermal cycling parameters were: $94^{\circ} \mathrm{C}$ for $3 \mathrm{~min}, 40^{\circ} \mathrm{C}$ for $5 \mathrm{~min}$ and $72^{\circ} \mathrm{C}$ for $5 \mathrm{~min}$ for 1 cycle; $95^{\circ} \mathrm{C}$ for $15 \mathrm{sec}, 40^{\circ} \mathrm{C}$ for $2 \mathrm{~min}$ and $72^{\circ} \mathrm{C}$ for $1 \mathrm{~min}$ for 35 cycles, then $72^{\circ} \mathrm{C}$ for $5 \mathrm{~min}$. The PCR-amplified fragments were separated on a $6 \%$ denaturing polyacrylamide gel containing $8 \mathrm{M}$ urea, and scanned using a FLA-2000 fluorescent image analyzer (Fuji Photo Film). Differentially expressed mRNA bands correlated with tumor malignancy were excised from the gels and re- amplified by PCR using a corresponding set of primers (anchor primer and random primers) under identical conditions. The resulting PCR products were electrophoresed on a $2.5 \%$ agarose gel containing $0.1 \%$ H.A.-Yellow (Takara Bio), and the gel was scanned using a FLA-2000 image analyzer. Markedly differentially expressed mRNA bands were excised from the agarose gels, and DNA was extracted, cloned into a PCRTM2.1 vector (Invitrogen) and transformed into DH5 $\alpha$ according to the manufacturer's instructions. Plasmids were sequenced using the BigDye Terminator Cycle on an Applied Biosystems DNA sequencer, model 377.

Northern blotting. For the analysis of rat $18 \mathrm{c}$, mRNA was purified from total RNA derived from ER-1, ER-1-24h, ER-1-1M and ERpP cells using oligotex-dT30 (Takara Bio). mRNA $(2 \mu \mathrm{g})$ from each cell line was electrophoresed on a $1 \%$ agarose gel containing $2.2 \mathrm{M}$ formaldehyde using MOPS buffer (0.02 M MOPS, pH 7.0, containing $5 \mathrm{mM}$ sodium acetate and $1 \mathrm{mM}$ EDTA). After washing the gel with $20 \mathrm{X}$ SSC (1X SSC consists of $0.15 \mathrm{M} \mathrm{NaCl}$ and $0.015 \mathrm{M}$ sodium citrate, pH 7.0), the RNA was blotted onto a Hybond $\mathrm{N}^{+}$ membrane (GE Healthcare) for $16 \mathrm{~h}$. The membrane was pretreated with hybridization buffer $[50 \%$ formamide, $5 \mathrm{X}$ standard saline phosphate/EDTA (SSPE; 0.15 M NaCl, $9.8 \mathrm{mM}$ phosphate, pH 7.4 and $1 \mathrm{mM}$ EDTA), $0.5 \%$ SDS, 5X Denhardt's solution and $0.5 \mathrm{mg}$ salmon sperm DNA in $5 \mathrm{ml}$ ] at $42^{\circ} \mathrm{C}$ for $1 \mathrm{~h}$ and then hybridized at $42^{\circ} \mathrm{C}$ for $20 \mathrm{~h}$ with the longest rat $18 \mathrm{c}$ and rat $\beta$-actin cDNAs, which had previously been labeled with $\left[\alpha-{ }^{32} \mathrm{P}\right] \mathrm{dCTP}\left(1.0 \times 10^{6} \mathrm{cpm} / \mathrm{ml}\right)$ using a Takara BcaBEST labeling kit (Takara Bio). The membrane was subsequently washed with $1 \mathrm{X}$ SSPE containing $0.1 \%$ SDS at $55^{\circ} \mathrm{C}$ for $20 \mathrm{~min}$ and with $0.1 \mathrm{X}$ SSPE containing $0.1 \%$ SDS at $55^{\circ} \mathrm{C}$ for $30 \mathrm{~min}$, followed by exposure to X-ray film.

For the analysis of human GGCT, human multiple tissue Northern (MTN) blots containing RNA from 12 different normal human tissues were used, as well as human tumor MTN blots containing RNA from 8 human tumor tissues (Clontech). MTN blots were pre-hybridized with ExpressHyb hybridization solution at $68^{\circ} \mathrm{C}$ for $30 \mathrm{~min}$, and then hybridized at $68^{\circ} \mathrm{C}$ for $1 \mathrm{~h}$ with $\left[\alpha^{-32} \mathrm{P}\right] \mathrm{dCTP}-$ labeled GGCT $\mathrm{cDNA}\left(1.0 \times 10^{7} \mathrm{cpm} /\right.$ $\mathrm{ml}$ ) that had previously been prepared as described above. The membrane was subsequently washed with 2X SSC (1.5 M $\mathrm{NaCl}$ and $0.15 \mathrm{M}$ sodium citrate, $\mathrm{pH} 7.0$ ) containing $0.05 \%$ $\mathrm{SDS}$ at room temperature for $40 \mathrm{~min}$ and with $0.1 \mathrm{X} \mathrm{SSC}$ containing $0.1 \% \mathrm{SDS}$ at $50^{\circ} \mathrm{C}$ for $40 \mathrm{~min}$, followed by exposure to X-ray film. The relative intensity of GGCT mRNA compared with $\beta$-actin mRNA was determined using the Image J program (http://rsbweb.nih.gov/ij/download.html).

Cloning of rat 18c. An ERpP cDNA library was constructed from mRNAs derived from ERpP cells using a SMART cDNA library construction kit (Clontech) according to the manufacturer's protocol. The 200-bp cDNA fragment of rat $18 \mathrm{c}$ was used as a probe for screening and was labeled by PCR $\left(94^{\circ} \mathrm{C}\right.$ for $1 \mathrm{~min}, 50^{\circ} \mathrm{C}$ for $2 \mathrm{~min}, 72^{\circ} \mathrm{C}$ for $3 \mathrm{~min}$ for 40 cycles and $72^{\circ} \mathrm{C}$ for $7 \mathrm{~min}$ ) using a digoxigenin DNA-labeling kit (Roche). Positive clones were isolated using a plaque hybridization method. The nucleotide sequences of rat $18 \mathrm{c}$ cDNA clones were determined using the BigDye Terminator Cycle. The DDBJ, EMBL and GenBank databases were searched 
using the BLAST algorithm (BLASTN, BLASTX and PSI-BLAST). The SMART program was used to perform a domain structure search.

Preparation of recombinant GGCT protein. To prepare the recombinant human GGCT protein, GGCT cDNA was subcloned into the pGEX6P1 plasmid (GE Healthcare) and used to transform Escherichia coli strain BL21. Expression of the glutathione S-transferase (GST)-GGCT fusion protein was induced by the addition of $0.1 \mathrm{mM}$ isopropyl $B-D$ thiogalactoside for $3.5 \mathrm{~h}$ at $30^{\circ} \mathrm{C}$ and solubilized in lysis buffer $(20 \mathrm{mM}$ Tris- $\mathrm{HCl}, \mathrm{pH} 8.0$, containing $1 \mathrm{mM}$ EDTA and $100 \mathrm{mM} \mathrm{NaCl}$ ). The recombinant GGCT protein was isolated from the extract by affinity chromatography on glutathione-Sepharose 4B beads (GE Healthcare) and subsequently by elution through digestion with PreScission protease (GE Healthcare) in buffer containing $20 \mathrm{mM}$ Tris$\mathrm{HCl}, \mathrm{pH} 7.0,150 \mathrm{mM} \mathrm{NaCl}, 0.1 \mathrm{mM}$ EDTA and $0.05 \mathrm{mM}$ dithiothreitol at $4^{\circ} \mathrm{C}$.

Preparation of polyclonal antibody against the recombinant GGCT protein. To obtain an antibody against GGCT protein, $300 \mu \mathrm{g}$ of recombinant GGCT protein were emulsified in Freund's complete adjuvant and injected s.c. into rabbits, followed by four booster injections. The antiserum was purified by affinity chromatography on Protein A-immobilized Sepharose CL-4B (GE Healthcare), and then on GGCTimmobilized resin that had been prepared by immobilizing the GGCT protein to a HiTrap NHS-activated cartridge (GE Healthcare) according to the manufacturer's protocol. Immunoreactivity was verified by Western blotting of the recombinant protein as described below.

Western blotting. Proteins were separated by SDS-PAGE on a $10 \%$ gel and transferred to a nitrocellulose membrane (Advantec), which was blocked with 5\% non-fat milk in phosphate-buffered saline (PBS) containing 0.1\% Tween-20 for $1 \mathrm{~h}$ at room temperature. The membrane was then incubated with the primary antibody at room temperature for $1 \mathrm{~h}$ and with a horseradish peroxidase-conjugated antibody against rabbit or mouse immunoglobulin at room temperature for $30 \mathrm{~min}$. The membrane was developed with an enhanced chemiluminescence detection system (GE Healthcare). The relative intensity of the GGCT protein compared with the $\beta$-actin protein was determined using the Image $\mathbf{J}$ program (http://rsbweb.nih.gov/ij/download.html).

Plasmid construction. Full-length human GGCT was inserted into the EcoRI-NotI sites of pCIneo-Flag, pCIneo-T7 (Promega) and pEGFP-C1 plasmids (Clontech) after subcloning of the full-length human GGCT containing the EcoRI and NotI sites by PCR using the primers: GGCT EcoRI forward, 5'-GAATTCATGGCCAACTCGGG-3' and GGCT Not I reverse, 5'-GCGGCCGCCTAAAGAGTTGT-3'. The PCR products were subcloned in the pGEM-T-vector (Promega). GGCT deletion mutants were generated by PCR using the primers: GGCT-s-vector, 5'-GTCGACCCGG GCGGCCGCTTC-3'; GGCT-s-361-381, 5'-ACCTGTCGAA GTTATCTGATG-3'; GGCT-as-360-340, 5'-TATTTCTTT TCCTTCTTGAGT-3'; GGCT-as-vector, 5'-GAATTCGCC
CATCTGCTGGCC-3'; GGCT-as-180-160, 5'-TGTTTTG CCTTGGGAATTGCC-3' and the Expand High Fidelity PCR System (Roche) according to the manufacturer's protocol.

Transfection. NIH3T3 and HEK293T cells were cultured in DMEM containing $10 \% \mathrm{FBS}$ at $37^{\circ} \mathrm{C}$ in a $5 \% \mathrm{CO}_{2}$ atmosphere. Transfection of the NIH3T3 cells was performed using Fugene 6 (Roche) and that of HEK293T cells using Metafectene (Biontex) according to the manufacturers' protocol.

Gel filtration. HEK293T cells transfected with pCIneo-FlagGGCT or non-transfected HEK293T cells in $200 \mu \mathrm{l}$ (wet volume) were washed with ice-cold PBS and lysed with $800 \mu \mathrm{l}$ of lysis buffer containing $50 \mathrm{mM}$ Tris- $\mathrm{HCl}, \mathrm{pH} 7.5$, $0.15 \mathrm{M} \mathrm{NaCl}, 1 \%$ Triton $\mathrm{X}-100$ and complete protease inhibitor cocktail (Roche). The cell lysate was centrifuged and filtered through a $0.2 \mu \mathrm{m}$ pore size filter. The resulting supernatant $(200 \mu \mathrm{l})$ was loaded onto a Superdex $200 \mathrm{HR}$ column $(1 \times 30 \mathrm{~cm})(\mathrm{GE}$ Healthcare) equilibrated with lysis buffer at $4^{\circ} \mathrm{C}$. Fractions $(400 \mu \mathrm{l})$ were collected, and overexpressed Flag-tagged GGCT and endogenous GGCT protein were detected by SDS-PAGE and Western blotting with antiFlag and -GGCT antibodies, respectively. Molecular mass standards (chymotrypsinogen A, $25 \mathrm{kDa}$; ovalbumin, $43 \mathrm{kDa}$ and bovine serum albumin, $67 \mathrm{kDa}$ ) were run under the same conditions to calibrate the column.

Immunoprecipitation. HEK293T cells were transfected with the indicated plasmids using Metafectene. Following a 36-h transfection, the cells were washed with ice-cold PBS and lysed with a buffer containing $50 \mathrm{mM}$ Tris- $\mathrm{HCl}, \mathrm{pH} 7.5,0.1 \mathrm{M}$ $\mathrm{NaCl}, 0.5 \%$ Triton $\mathrm{X}-100$ and complete protease inhibitor cocktail. The cell lysate was centrifuged and the resulting supernatant was incubated with anti-Flag M2 affinity gel (Sigma-Aldrich) for $2 \mathrm{~h}$ at $4^{\circ} \mathrm{C}$. The immunocomplex produced was washed five times with lysis buffer, and was then subjected to SDS-PAGE and subsequently to Western blotting with anti-Flag tag or anti-T7 tag antibody (Merck).

Fluorescence microscopy. NIH3T3 cells were transfected with pEGFP-C1-GGCT or deletion mutants. After $24 \mathrm{~h}$ incubation, the cells were washed with PBS and fixed with $4 \%$ paraformaldehyde in PBS for $1 \mathrm{~h}$ at $4^{\circ} \mathrm{C}$. After being washed twice with PBS, the specimen was stained with 4',6-diamidino-2phenylindol (DAPI) in PBS for 5 min at room temperature and then washed with PBS. Fluorescence due to green fluorescent protein (GFP) and DAPI was observed using a Zeiss LSM510 confocal laser scanning fluorescence microscope.

Colony formation assay. To establish the cells that stably expressed Flag-tagged GGCT and Flag tag alone, HBL-100 cells were transfected with pCIneo-Flag-GGCT and pCIneoFlag using Metafectene. Following a 36-h transfection, the cells were cultured with $500 \mu \mathrm{g} / \mathrm{ml}$ geneticine (Invitrogen) for three weeks to generate the Flag-GGCT-HBL-100 and Flag-HBL-100 cells, respectively. GGCT protein expression was confirmed by Western blotting with anti-GGCT antibody.

A soft agar colony formation assay was carried out to assess the anchorage-independent growth ability of stable Flag-GGCT-HBL-100 and Flag-HBL-100, NIH3T3 and 
A

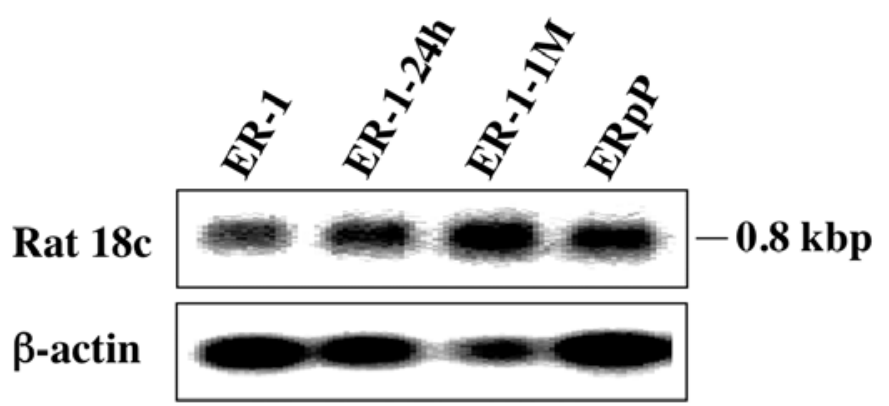

B

1

Rat $18 \mathrm{C}$

Human GGCT

------------ETFLYFAYGSNLLTERIHLRNPSAVFCCVARLODFKLDFGNFOGKM

MANSGCKDVTGPDEESFLYFAYGSNLLTERIHLRNPSAAFFCVARLQDFKLDFGNSQGKT $* * * * * * * * * * * * * * * * * * * * * * * * * * * * * * * * * * * * * * * * *$

61 SERWHGGIATIFQSPGDEVWGVVWKMNKSNLSSLDEQEGVKSGVYVVIEIKVTTQQGKDI 120

Rat $18 \mathrm{c}$

Human GGCT SQTWHGGIATIFQSPGDEVWGVVWKMNKSNLNSLDEQEGVKSGMYVVIEVKVATQEGKEI

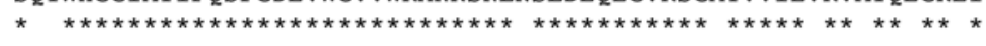

1212180

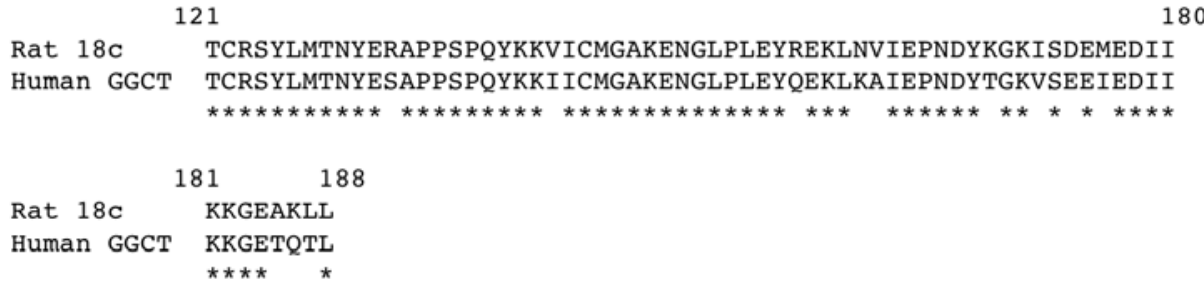

Figure 1. Rat 18c gene expression and multiple alignments of the amino acid sequence of rat 18c and its human homolog GGCT protein. (A) Northern blot analysis showed that rat 18c mRNA levels were increased in EGF-treated ER-1 (ER-1-24h and ER-1-1M) and ERpP cells, compared with the levels observed in ER-1 cells. (B) Multiple sequence alignments were carried out using a default option within ClustalW.

SW480 cells. Five thousand cells were suspended in $0.4 \%$ low melting temperature agarose (Takara Bio) containing DMEM and $10 \%$ FBS, and were plated over a base layer of $0.53 \%$ low melting temperature agarose containing DMEM and $10 \% \mathrm{FBS}$ in a $60 \mathrm{~mm}$ dish. After a 10-day incubation, the colony numbers were counted in triplicate experiments.

\section{Results and discussion}

To identify genes related to tumor progression, we used rat ER-1 cells and their derivatives (4-9). ER-1 cells derived from a rat mammary adenocarcinoma cell line show weak tumorigenicity and lack metastatic ability, while EGF-treated ER-1 cells (ER-1-24h and ER-1-1M) possess tumorigenic and metastatic properties. ERpP cells, established from tumors arising from plate-attached ER-1 cells, possess strong tumorigenic and metastatic properties. Through differential display analysis, we identified several rat genes whose expression was increased in EGF-treated ER-1 and ERpP cells compared with the expression levels observed in the original ER-1 cells. We focused on the gene rat $18 \mathrm{c}$, investigating its expression levels in the cells ER-1, ER-1-24h, ER-1-1M and ERpP using Northern blot analysis (Fig. 1A). The size of rat 18c mRNA was around $-0.8 \mathrm{kbp}$, and its expression level was increased in EGF-treated ER-1 (ER-1-24h and ER-1-1M) and ERpP cells compared with levels in ER-1 cells. We then obtained a full- length cDNA clone encoding rat $18 \mathrm{c}$ from the ERpP cDNA library using a differential display fragment as a probe. The longest insert obtained consisted of $730 \mathrm{bp}$ and was predicted to encode a protein of 174 amino acid residues. BLAST analysis revealed that rat $18 \mathrm{c}$ is an ortholog of the human gene C7orf24 (accession ID BC019243), which is located at openreading frame 24 of chromosome 7 . The human $\mathrm{C} 7$ orf 24 cDNA clone is 1189 bp long and encodes a protein of 188 amino acids. Recently, C7orf2 4 was identified as $\gamma$-glutamyl cyclotransferase (GGCT) (12). The amino acid alignment of rat $18 \mathrm{c}$ and human GGCT is shown in Fig. 1B. According to SMART and other databases, neither rat $18 \mathrm{c}$ nor human GGCT possesses any predicted structural protein domains or nuclear localization signals.

In order to clarify the roles of rat $18 \mathrm{c}$ and human GGCT in tumor progression, the human GGCT gene was subsequently studied. To characterize GGCT mRNA expression, Northern blot analysis was performed using RNAs derived from various normal and tumor human tissues (Fig. 2A and B). It was found that GGCT mRNA was expressed in various normal tissues, including skeletal muscle, brain, heart, colon, thymus, kidney, liver and placenta, while its expression was undetectable in the small intestine, lung and peripheral blood leukocytes. However, in tumor tissues expression was detected in tumors of the lung, uterus, breast, ovary, stomach and rectum, but not in kidney and colon tumors. Table I shows the relative 
Table I. Expression levels of GGCT mRNA in human normal and tumor tissues.

\begin{tabular}{|c|c|c|}
\hline Tissue & $\begin{array}{c}\text { Relative intensity } \\
\text { of GGCT mRNA } \\
\text { (GGCT/ß-actin) }\end{array}$ & $\begin{array}{c}{ }^{\mathrm{a} G G C T} \\
\text { transcripts } \\
\left.\text { (per } 10^{6} \mathrm{ESTs}\right)\end{array}$ \\
\hline Brain & 0.31 & 18 \\
\hline Heart & 0.13 & 22 \\
\hline Skeletal muscle & 0.37 & 78 \\
\hline Colon & 0.12 & 49 \\
\hline Colon tumor & 0.00 & 46 \\
\hline Thymus & 0.08 & ${ }^{\mathrm{b}} \mathrm{ND}$ \\
\hline Spleen & 0.02 & 18 \\
\hline Kidney & 0.12 & 75 \\
\hline Kidney tumor & 0.00 & 100 \\
\hline Liver & 0.10 & 76 \\
\hline Small intestine & 0.08 & 0 \\
\hline Placenta & 0.47 & 10 \\
\hline Lung & 0.07 & 37 \\
\hline Lung tumor & 0.48 & ND \\
\hline Leukocyte & 0.06 & ND \\
\hline Mammary gland & ND & 70 \\
\hline Mammary gland tumor & ND & 97 \\
\hline Breast tumor & 0.56 & ND \\
\hline Ovary & ND & 37 \\
\hline Ovary tumor & 0.27 & ND \\
\hline Uterus & ND & 62 \\
\hline Uterus tumor & 0.37 & ND \\
\hline Stomach & ND & 48 \\
\hline Stomach tumor & 0.02 & ND \\
\hline Rectum tumor & 0.03 & ND \\
\hline
\end{tabular}

${ }^{\mathrm{a} D}$ ata from the previous report (12). ${ }^{\mathrm{b}} \mathrm{ND}$, not determined.

intensity of GGCT mRNA expression from Northern blot analysis (Fig. 2A and B) and the number of EST counts of GGCT in various normal human and tumor tissues in the previously reported results (12). Both pieces of data indicated that the GGCT gene was expressed in various normal and tumor tissues, and that most tissues showed no difference between GGCT expression levels in tumor and normal cells, e.g., colon vs. colon tumor, kidney vs. kidney tumor (our study) and mammary gland vs. mammary gland tumor (previously reported study) (Table I). The exception was the case of lung vs. lung tumor in our study. The difference in the GGCT expression levels in lung vs. lung tumor suggests that GGCT is a potential clinical marker for lung tumors. Similar results have previously been reported, revealing that GGCT expression was not detected in 19 normal human lung tissues, while a high level of GGCT expression was detected in 8 samples among 20 lung tumor tissues (11). We further analyzed GGCT protein expression in various cancer cell lines
A

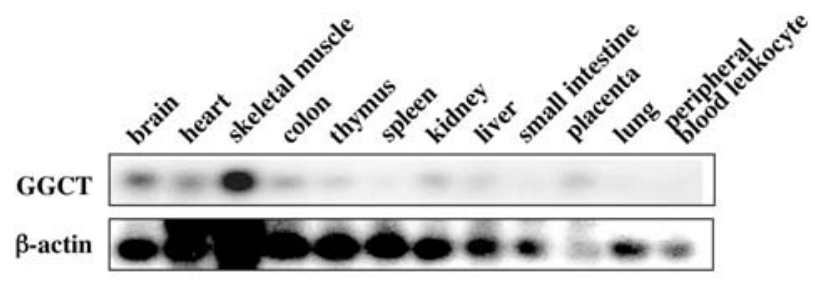

B

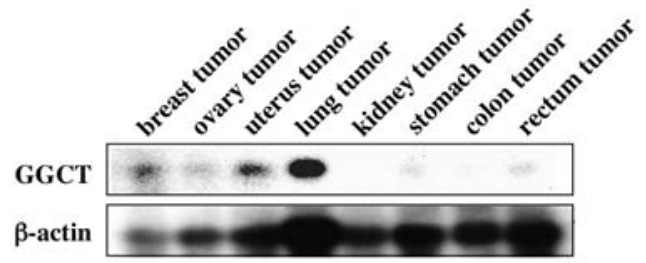

C

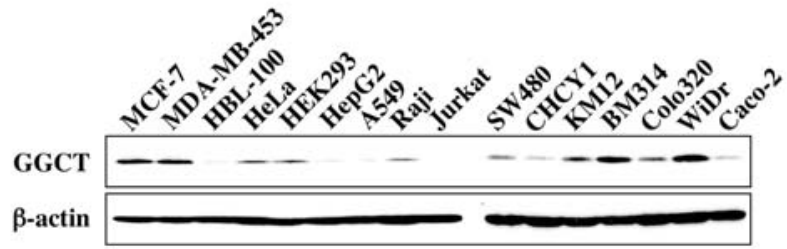

Figure 2. GGCT gene expression in human normal and tumor tissues and occurrence of GGCT protein in tumor cell lines. (A) Northern blot analysis was performed using the human multiple tissue northern (MTN) blots containing RNAs from 12 different normal human tissues, with the coding regions of the human GGCT and $\beta$-actin (control) cDNAs as probes. (B) Northern blot analysis using the human tumor MTN blots containing RNAs from 8 human tumor tissues. (C) Western blot analysis of cell extracts was performed using anti-GGCT and anti-human $\beta$-actin (control) antibodies.

by Western blotting with anti-GGCT antibody (Fig. 2C). Endogenous GGCT protein was detected at various levels in the cancer cell lines tested (Table II), and its expression levels appear to be independent of tumorigenicity and metastatic potential.

To determine whether GGCT protein interacts with other cell proteins, the cell lysates obtained from HEK293T cells transfected with pCIneo-Flag-GGCT or from non-transfected HEK293T cells were subjected to gel filtration and Western blotting with anti-Flag tag and anti-GGCT antibodies. As shown in Fig. 3A, both the overexpressed GGCT, detected by anti-Flag tag antibody, and the endogenous GGCT protein, detected by anti-GGCT antibody, emerged in almost the same fractions with molecular masses of 43 and $34 \mathrm{kDa}$, but not in the fraction with a molecular mass of $21 \mathrm{kDa}$, as was expected for the monomer. The 43-kDa complex is presumably composed of a homodimer of the GGCT protein, as previously proposed by a crystallographic study of recombinant GGCT protein (12). Regarding the $34-\mathrm{kDa}$ complex, we assume that it is formed by GGCT and (an) other protein(s) in the cell lysate, but as yet have no evidence verifying this. To confirm the dimerization of the GGCT protein inside the cell, we coexpressed Flag- and T7-tagged GGCT proteins in HEK293T cells. The extracts of the transfected cells were subjected to immunoprecipitation using anti-Flag tag antibody followed by Western blotting with anti-Flag tag and anti-T7 tag antibodies (Fig. 3B). As expected, the GGCT protein was found to interact with itself inside the cell. 
Table II. Expression levels of GGCT protein in various cell lines.

\begin{tabular}{|c|c|c|}
\hline Cell line & $\begin{array}{c}\text { Relative intensity of } \\
\text { GGCT mRNA } \\
\text { (GGCT/ß-actin) }\end{array}$ & Original tissue \\
\hline MCF-7 & 0.69 & Breast \\
\hline MDA-MB-453 & 0.65 & Breast \\
\hline HBL-100 & 0.01 & Breast \\
\hline HeLa & 0.18 & Cervix \\
\hline HEK293 & 0.21 & Embryonic kidney \\
\hline HepG2 & 0.01 & Liver \\
\hline A549 & 0.00 & Lung \\
\hline Raji & 0.10 & $\begin{array}{c}\text { Burkitt's lymphoma } \\
\text { (maxilla) }\end{array}$ \\
\hline Jurkat & 0.00 & $\begin{array}{l}\text { T-cell leukemia } \\
\text { (blood) }\end{array}$ \\
\hline SW480 & 0.13 & Colon \\
\hline CHCY1 & 0.04 & Colon \\
\hline KM12 & 0.26 & Colon \\
\hline BM314 & 0.59 & Colon \\
\hline Colo320 & 0.16 & Colon \\
\hline WiDr & 0.57 & Colon \\
\hline Caco-2 & 0.05 & Colon \\
\hline
\end{tabular}

A

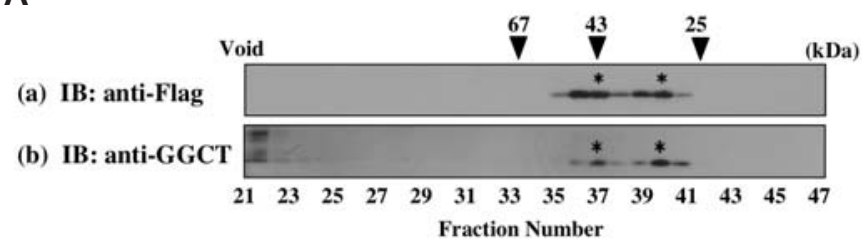

B

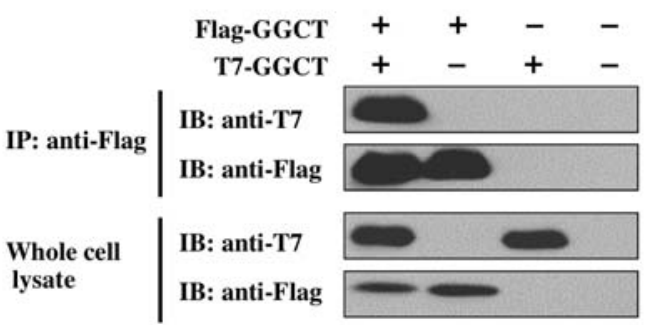

Figure 3. Dimerization of GGCT protein. (A) The cell lysate from HEK293T cells expressing flag-tagged GGCT (a) of non-transfected HEK293T cells (b) was subjected to gel filtration on a Superdex $200 \mathrm{HR}$ column $(1 \times 30 \mathrm{~cm})$ equilibrated with buffer containing $50 \mathrm{mM}$ Tris- $\mathrm{HCl}$, $\mathrm{pH} 7.5,0.15 \mathrm{M} \mathrm{NaCl}, 1 \%$ Triton $\mathrm{X}-100$ and complete protease inhibitor cocktail at $4^{\circ} \mathrm{C}$. Each fraction $(400 \mu \mathrm{l})$ was analyzed by SDS-PAGE and immunoblotting (IB) with anti-Flag tag (a) or anti-GGCT antibody (b). (B) HEK293T cell extract expressing flag-tagged GGCT, T7-tagged GGCT or both was subjected to immunoprecipitation (IP) with anti-Flag tag antibody and to IB with anti-T7 tag and anti-Flag tag antibodies. Whole cell lysate was also subjected to IB as a control.
A

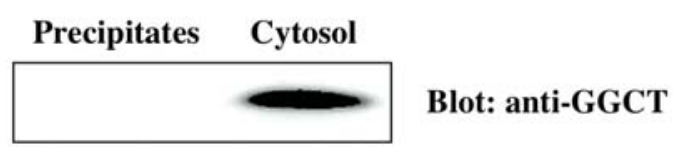

B
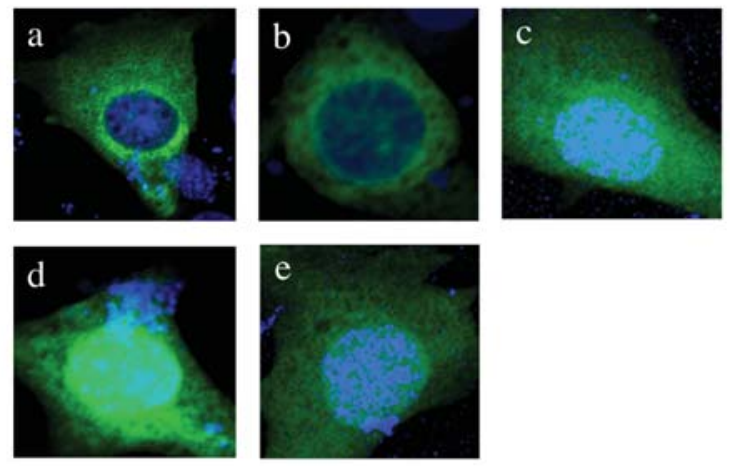

(a) GGCT (1-188)

(b) GGCT (1-120)

(c) GGCT (121-188)

(d) GGCT ( $\Delta 61-120)$

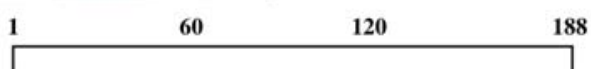

Figure 4. Cellular localization of GGCT protein and its truncated mutants. (A) Endogenous GGCT protein was detected in the cytosol fraction of MDAMB-453 cells, but not in the precipitate fraction, by Western blotting with anti-GGCT antibody. (B) NIH3T3 cells expressing four GFP-GGCT fusion proteins, GFP-GGCT (1-188) (a), GFP-BC019243 (1-120) (b), GFP-GGCT $(121-188)(c)$ GFP-GGCT $(\Delta 61-120)(d)$, and GFP (e), were fixed and stained for DNA using DAPI. Fluorescence due to GFP and DAPI was observed.

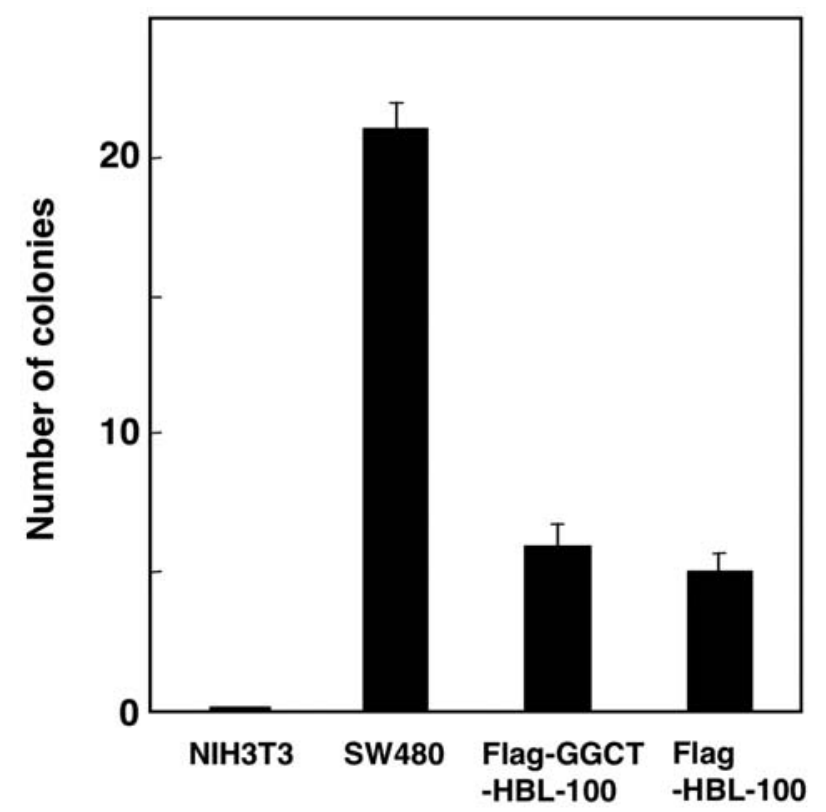

Figure 5. Non-tumorigenic activity of GGCT. Colony formation assays were performed using HBL-100 cells stably expressing Flag-tagged GGCT protein (Flag-GGCT-HBL-100) and Flag tag alone (Flag-HBL-100), as well as NIH3T3 and SW480 cells. Five thousand cells were suspended in $0.4 \%$ soft agarose over a base layer of $0.53 \%$ soft agarose. After a 10-day incubation, the number of colonies was counted. Experiments were performed in triplicate. Error bars indicate the standard deviation. 
To investigate the intracellular localization of the endogenous GGCT protein, MDA-MB-453 cell lysate was separated into cytosolic and precipitate fractions by ultra-centrifugation $\left(100,000 \mathrm{x} \mathrm{g} ; 1 \mathrm{~h}, 4^{\circ} \mathrm{C}\right)$, and both fractions were subjected to Western blot analysis with anti-GGCT antibody. Endogenous GGCT protein was only detected in the cytosolic fraction (Fig. 4A). In order to identify the region of GGCT protein required for its intracellular localization, we expressed GFPfused full-length and deletion mutants of GFP-GGCT in NIH3T3 cells (Fig. 4B). Full-length GGCT, GFP-GGCT (1-188) (a) and (1-120) (b) were detected only in the cytoplasm, while GFP-GGCT (121-188) (c) and (D61-120) (d) were detected in the nucleus and the cytoplasm. These results suggest that the region consisting of 61-120 amino acids is required for the full-length GGCT protein to anchor in the cytoplasm, and that deletion of the above region allows this protein to move to the nucleus, although the protein lacks the sequence characteristic of a so-called nuclear localization signal. It has been reported that a potential active site pocket of GGCT contains a highly conserved glutamic acid at position $98\left(\mathrm{Glu}^{98}\right)$, and that the mutation of $\mathrm{Glu}^{98}$ to Ala or Gln completely inactivated the enzyme without altering its overall structure (12). Thus, the region consisting of amino acids 61-120 that includes $\mathrm{Glu}^{98}$ is important in the functional localization of the GGCT protein.

In order to measure the tumorigenic activity of GGCT, we performed a colony formation assay using soft agar. The comparison of the colony formation of HBL-100 cells stably expressing Flag-tagged GGCT with that of HBL-100 cells stably expressing Flag tag alone (control) revealed that GGCT does not promote colony formation (Fig. 5). No difference was found in the proliferation rate of HBL-100 cells stably expressing GGCT compared with control HBL-100 cells (data not shown). These results strongly suggest that GGCT has little tumorigenic activity. It has been reported that there are many orthologs of human GGCT in other organisms, not only in mammals but also in chicken, fish, fly, nematodes and sea urchin (12). Thus, it can be inferred that the GGCT protein has common biological functions other than tumorigenesis.

Further study is needed to identify the role of GGCT during the multi-step process through which tumor cells acquire malignant properties. Our initial differential display analysis has identified many genes that are differentially expressed in ER-1 and ERpP cells. In a future study, we intend to perform DNA microarray analysis to investigate global gene expression in ERpP cells, and to compare it to the same expression in ER-1 cells. This will further extend our understanding of the gene networks involved in tumor progression.

\section{Acknowledgements}

This work was supported in part by Grants-in-Aid for Scientific Research (C) (14572046) from the Japan Society for the Promotion of Science (JSPS). The authors thank Drs Masanobu Kobayashi and Tetsuya Moriuchi of Hokkaido University for their useful discussions.

\section{References}

1. Foulds L: Tumor progression. Cancer Res 17: 355-356, 1957.

2. Nowell PC: Mechanisms of tumor progression. Cancer Res 46: 2203-2207, 1986.

3. Nicolson GL: Tumor cell instability, diversification and progression to the metastatic phenotype: from oncogene to oncofetal expression. Cancer Res 47: 1473-1487, 1987.

4. Ren J, Hamada J, Okada F, Takeichi N, Morikawa K, Hosokawa M and Kobayashi H: Ultrastructural differences in junctional intercellular communication between highly and weakly metastatic clones derived from rat mammary carcinoma. Jpn J Cancer Res 81: 920-926, 1990.

5. Hamada J, Takeichi N, Okada F, Ren J, Li X, Hosokawa M and Kobayashi H: Progression of weakly malignant clone cells derived from rat mammary carcinoma by host cells reactive to plastic plates. Jpn J Cancer Res 83: 483-490, 1992.

6. Li X, Nagayasu H, Hamada J, Hosokawa M and Takeichi N: Enhancement of tumorigenicity and invasion capacity of rat mammary adenocarcinoma cells by epidermal growth factor and transforming growth factor-beta. Jpn J Cancer Res 84: 1145-1149, 1993.

7. Hamada J, Nagayasu H, Kawano T, Mizutani T, Nakata D, Hosokawa $\mathrm{M}$ and Takeichi $\mathrm{N}$ : Characterization of the progressive sublines derived from a weakly malignant cloned cell line, ER-1, co-inoculated subcutaneously with a foreign body. Clin Exp Metastasis 16: 291-298, 1998.

8. Hamada J, Nagayasu H, Takayama M, Kawano T, Hosokawa M and Takeichi N: Enhanced effect of epidermal growth factor on pulmonary metastasis and in vitro invasion of rat mammary carcinoma cells. Cancer Lett 89: 161-167, 1995.

9. Nakata D, Hamada J, Ba Y, Matsushita K, Shibata T, Hosokawa M and Moriuchi T: Enhancement of tumorigenic, metastatic and in vitro invasive capacity of rat mammary tumor cells by transforming growth factor-beta. Cancer Lett 175: 95-106, 2002.

10. Masuda Y, Maeda S, Watanabe A, Sano Y, Aiuchi T, Nakajo S, Itabe $\mathrm{H}$ and Nakaya $\mathrm{K}$ : A novel 21-kDa cytochrome c-releasing factor is generated upon treatment of human leukemia U937 cells with geranylgeraniol. Biochem Biophys Res Commun 346: 454-460, 2006.

11. Xu L, Geman D and Winslow RL: Large-scale integration of cancer microarray data identifies a robust common cancer signature. BMC Bioinformatics 8: 275, 2007.

12. Oakley AJ, Yamada T, Liu D, Coggan M, Clark AG and Board PG: The identification and structural characterization of C7orf24 as gamma-glutamyl cyclotransferase. An essential enzyme in the gamma-glutamyl cycle. J Biol Chem 283: 22031-22042, 2008.

13. Azumi K, Sasaki T, Okouchi K, Yamasaki S, Saito T, Takayama H and Yokosawa H: Differential display analysis reveals the expression of glutathione S-transferase omega and novel genes through an ITAM-containing receptor in ascidian immunocytes. Immunogenetics 57: 444-452, 2005. 